TITLE

\title{
Randomized controlled trial of cognitive-motivational therapy program (PIPE) for the initial phase of schizophrenia: maintenance of efficacy at 5-year follow up
}

\section{Author names and affiliations.}

Palma, C. ${ }^{a, b}$; Farriols, Na,b; Frías, A. ${ }^{a, b .}$ Cañete, J. ${ }^{a, b}$, Gomis, $\mathrm{O}^{1}$., Fernández, $\mathrm{M}^{1}$., Alonso, I. B, Signo, $S^{2}$.

a Department of Psychology, FPCEE Blanquerna, Ramon Llull University. Barcelona Spain.

${ }^{b}$ Department of Mental health, Hospital de Mataró. Barcelona Spain

*Corresponding author. Carol Palma Sevillano. E-mail: carolinaps@blanquerna.url.edu. FPCEE Blanquerna, Universitat Ramon Llull. Císter, 34 (08022). Barcelona (Spain). Phone: +34932533000. Department of Psychiatry Hospital de Mataró.Carretera de Cirera s/n (08304). Barcelona (Spain).

The authors have declared that they have no conflicts of interest in relation to the subject of this study.

\section{Introduction}

Cognitive Behavioral Therapy (CBT) has been shown by numerous studies to be an effective treatment for schizophrenia (Pfammatter, Junghan, \& Brenner, 2006; Rothwell \& Duffy, 1999; Turner, van der Gaag, Karyotaki, \& Cuijpers, 2014). However, this treatment provides patients with only modest benefits in terms of reduction in symptoms, and the effects of the treatment are only moderate in size (Sivec \& Montesano, 2012; Westermann \& Cavelti, 2015). Interventions carried out during the critical initial phases of the disorder have met with promising results (Lutgens et al., 2015). Among the chief limitations faced by this sort of treatment are high rates of both abandonment of therapy and of poor therapeutic compliance. There is also a lack of consensus as to the prevention of relapses, and the therapy is thought to bring about only a partial improvement in quality of life. A meta-analysis lent support to beliefs about the limitations of CBT, showing inconclusive results for this sort of therapy (compared with other unspecified control interventions) in terms of symptomatic improvement and prevention of relapses(Lynch, Laws, \& McKenna, 2010). 
Recently, a number of studies have looked at how to employ other therapeutic elements along with CBT in order to overcome the limitations faced by this therapeutic strategy. For example, some researchers have looked at combining CBT with compassionate mind training therapy (CMT) (Beaumont, Galpin, \& Jenkins, 2012), while others have examined the use of motivational interventions in cognitive therapy programs to treat psychosis (Barrowclough et al., 2001; Wai, Mui, Cheung, \& Gray, 2015). In fact, patents' degree of motivation to start and maintain the therapy process has been found to play a critical role in determining the prognosis of a disorder (Jochems, van Dam, Duivenvoorden, Scheffer, van der Feltz-Cornelis \& Niels, 2015).

Motivational interview (MI) were initially designed for substance abuse treatment (Miller \& Rollnick, 1991),but they have also been applied to the treatment of schizophrenia. Some research has shown this method to be effective, although most of the existing evidence does concern substance abuse (Baker et al., 2002; Graeber, Moyers, Griffith, Guajardo, \& Tonigan, 2003; La Pietra, 2006; Martino, Carroll, Nich, \& Rounsaville, 2006; Martino et al., 2000; Steinberg, Ziedonis, Krejci, \& Brandon, 2004; Swanson, Pantalon, \& Cohen, 1999), adherence to pharmacological treatment regimens (Depp, Lebowitz, Lacro, \& Jeste, 2007; Drake et al., 2015; Fiszdon, Kurtz, Choi, Bell, \& Martino, 2016; Kemp, Hayward, Applewhaite, Everitt, \& David, 1996; Kemp, Kirov, Everitt, Hayward, \& David, 1998; McCracken \& Corrigan, 2008; O'Donnell et al., 2003; Rusch \& Corrigan, 2002) and encouragement of physical exercise(Beebe et al., 2011, 2012; Farholm \& Sørensen, 2016). Other studies along similar lines have looked at aspects such as goal assessment (Corrigan, McCracken, \& Holmes, 2001)and the development of insight (Rusch \& Corrigan, 2002).

Motivational techniques derived from MI can be incorporated into all the components of a treatment program, and they can be used at different points throughout the treatment process (McCracken \& Corrigan, 2008). Thus, the intervention style used by a therapist has far-reaching effects that are felt throughout the treatment process (Corrigan et al., 2001). This model is founded upon a body of knowledge that suggests that improved clinical results can be achieved by combining motivational techniques with other strategies, including cognitive therapy, as part of a treatment plan for patients with schizophrenia (Barrowclough, 2011; Barrowclough et al., 2010, 2014; Garety, Fowler, \& Kuipers, 2000; Kuipers et al., 1997; Westra, Aviram, \& Doell, 2011). A series of studies by Barrowclough et al. $(2001,2011,2014)$ have provided evidence for the clinical effectiveness of these strategies after treatment, both in terms of positive and negative symptoms. These interventions have also been shown to be effective at contributing to improvements in overall activity and general clinical impressions of patients in treatment (Barrowclough et al., 2001; Haddock et al., 2003) and at curbing relapses (Bechdolf \& Pohlmann, 2012b; Sellwood et al., 2001; Wai et al., 2015).

Elsewhere, the incorporation of motivational interview techniques into family therapy has also yielded promising results (Keet, Hulstijn, de Haan, Schippers, \& Linszen, 2006). One of the best-known treatments for initial episodes is Cognitive Enhancement Therapy (CET) (Miller \& Mason, 2004), which uses a motivational approach to foster improvements in cognitive symptoms. This technique 
combines supportive psychotherapy with work on social skills and cognitive remediation training. A number of studies over the past 10 years have pointed to the effectiveness of this therapeutic strategy (Dolder et al., 2003; Eack, Greenwald, Hogarty, \& Keshavan, 2010; Eack, Mesholam-Gately, Greenwald, Hogarty, \& Keshavan, 2013; Eack, Hogarty, Bangalore, Cornelius, \& Keshavan, 2016; Eack, Newhill, \& Keshavan, 2016; Keshavan, Eack, Prasad, Haller, \& Cho, 2016; Wojtalik et al., 2016). Other studies have included motivational interventions in the family therapy process via a technique called Hallucination Focused Integrative Treatment (Jenner, Nienhuis, Wiersma, \& van de Willige, 2004). Patients treated using this method showed significant improvements in quality of life, with even greater gains in social functioning (Wiersma, Jenner, Nienhuis, Stant, \& van de Willige, 2004). It seems reasonable to conclude that when therapy helps engender intrinsic motivations to engage in healthy conduct, the long-term clinical outcomes are better and longer lasting, and there are positive effects in terms of fewer relapses and greater adherence to pharmacological regimes (Jackson et al., 2001; Johannessen, Larsen, McGlashan, \& Vaglum, 2000).

Despite all the results described above, there remains a need for further empirical studies of the effectiveness of the use of motivational interviews with these patients. Among the gaps in the existing research is a lack of experiments demonstrating the lasting benefits of such techniques throughout the therapeutic process and of research into how they can be incorporated into a comprehensive treatment program (Rusch \& Corrigan, 2002). There are also no long-term studies demonstrating the sustainability of the results (Barrowclough et al., 2001; Bertelsen et al., 2008; Sivec \& Montesano, 2012). In light of these gaps in the research, an integrated program based on motivational interviews was developed (Palma, 2015)in order to be applied to the treatment of initial episodes. A study of patients in the initial phase of schizophrenia was conducted in order to assess the effectiveness of this program and showed good results 6 months after the start of treatment (Palma et al., 2011).

This study presents the results obtained 6 and 12 months after treatment and then those collected upon follow-up measurements taken 18 months and then 5 years later, with data gathered on clinical improvements, everyday functioning and relapses of patients treated during the initial phase of schizophrenia.

\section{Methods}

\subsection{Trial design}

A randomized, controlled, single-blind clinical trial was carried out. The main goal was to evaluate the effectiveness of the cognitive motivational program. Assessment of subjects was carried out before each was randomly assigned to one of the two conditions in the clinical trial: (a) PIPE program plus routine care; and (b) routine care only. An external researcher-epidemiologist using a computer program (IBM SPSS software Statistics 22) carried out randomization and allocation of subjects. 
Clinical assessments were performed at baseline, post-treatment (6 months and 1 year, with follow-ups at 18 months and 5 years). All patients received routine care during the treatment and followup period. The psychologists who assessed outcomes were blinded to group allocation.

\subsection{Selection of patients and group allocation}

The inclusion criteria were: (a) patients had to be in the initial phase of schizophrenia $(<3$ years from the first episode) and must not have been diagnosed with schizoaffective disorder, intellectual disabilities or language difficulties; (b) they had to be users of the Mataró Mental Health Service (Barcelona). Diagnoses were established by two experienced professionals based on the Structured Clinical Interview for DSM-IV Axis I Disorders (SCID)(American Psychiatric Association, 2000)and a review of the clinical history.

Participants were identified through a central computerized database that collects contacts with local health services, including admissions into the Hospital of Mataró, visits to emergency services, outpatient consultations, visits to the Mental Health Centre, and admissions into the Day Hospital in Mataró. Patients and their families were contacted and invited to participate in the study and had to sign a consent form.

A total of 104 cases of patients diagnosed with schizophrenic disorder who met the inclusion criteria for this study were recruited. During the enrollment process, 5 subjects were excluded (false positives); 7 people didn't meet the inclusion criteria and 30 did not agree to participate in the study due to lack of insight. At last, the total sample was composed by 62 patients.

\subsection{Interventions}

\subsubsection{Integrated intervention program (PIPE)}

The intervention program lasted for 12 months, with a total of 34 (weekly) sessions (of 45 minutes each), carried out at the Mental Health Centre. The PIPE early intervention program consists of three different therapeutic components: psychoeducation and cognitive- motivational therapy conducted with both the individual and the family. The PIPE program has been described elsewhere (Palma, 2015).

Motivational techniques were used to increase patients' motivation to change, help them overcome their ambivalence about treatment, promote their adherence to both pharmacological and psychological treatment, change substance use habits (in the case of patients who used drugs), increase daily life activities, maintain hygiene habits (in the case of patients with difficulties in this area), treatment compliance, and increase their desire to start to engage in occupational activities. These techniques were combined with cognitive therapy (e.g., cognitive restructuration, exposition, coping strategies of delusions and/or hallucinations). The techniques of the IM promote change processes to 
generate an intrinsic motivation in its different phases (precontemplative, contemplative, active phase, maintenance and / relapse) (Palma, Cebrià, Farriols, Cañete, \& Muñoz, 2005).

Individual CBT was used to treat delusional ideas and beliefs, hallucinations, neurotic cognitive biases, and obsessive and co-morbid symptoms (depression and anxiety) (Birchwood \& Tarrier, 1995). Family intervention was aimed at fostering attitudes conducive to communication (reduce expressed emotion) and at promoting improved adaptation to the illness within the family. As in the individual therapy, the goal of the work with the family was to promote healthy and functional changes, in accordance with MI. The intervention program is described below.

Four psychoeducational sessions were carried out with patients and their families, as well as twenty sessions of individual cognitive-motivational intervention and 10 sessions of family therapy. In some of these sessions, the whole family (parents, siblings and the patient) took part, whereas other sessions involved certain family members at the therapist's discretion (friends, aunts or uncles and grandparents).

Therapists trained in the MI carried out the interventions. They were clinical psychologists with extensive experience in the treatment of psychosis. Regular supervisions were carried out, some of them with audiovisual support.

\subsubsection{Control group (GC)}

The patients received the usual treatment for the initial phase of schizophrenia offered by the Spanish Mental Health Care system, namely pharmacological treatment prescribed by a regular psychiatrist. Nursing care and interventions by social workers were also included monthly. The intervention consisted of quarterly visits in psychiatry to perform the pharmacological follow-up. The nursing visits were carried out monthly to improve health care, diet and compliance to the treatment. The topics related to the increase of occupational activity were treated with social work with a quarterly frequency. Psychologists participated only where specific assessments or intervention were necessary.

\subsection{Assessment procedures and instruments}

Assessments of clinical results, everyday functioning and relapses were performed 5 times: pretreatment, after 6 months, post-treatment (12months), and in follow-up measurements: after 18 months and 5 years.

Qualified external raters carried out assessments in order to guarantee single-blinding (psychologists). In order to ensure the greatest possible degree of inter-rater reliability, these assessors were given training in the use of the instruments applied in this study. Data on the social and demographic characteristics of the patients and their families were collected via short questionnaire administered during the first interview and via the review of clinical history.

\subsubsection{Symptoms and overall functioning}

- Baseline assessment 
The instruments used in the baseline clinical assessment included the Spanish translation of the Structured Clinical Interview for DSM-IV Axis I Disorders, Research Version, Patient Edition (SCID$\mathrm{I} / \mathrm{P})$. It is a semi-structured interview an disused for making lifetime DSM-IV Axis I diagnoses of several comorbid disorders (First, Spitzer, Gibbon, \& Williams, 1995). Also included was the Spanish version of the Positive and Negative Syndrome Scale (PANSS) (Kay, Fiszbein, \& Opler, 1987), which had previously been shown to be a reliable instrument for assessing the severity of psychotic symptoms (Peralta \& Cuesta, 1994). Functioning was assessed using the EEAG (American Psychiatric Association, 2000) scale and the Global Assessment of Functioning Scale (National Institute of Mental Health, 1976).

- Assessments during the course of treatment

Six months after the beginning of the intervention, the PANSS was administered to observe the patients' progress. The assessments conducted during the period of treatment were carried out by the same raters who had performed the baseline evaluations.

\subsubsection{Relapses}

So as to avoid falling victim to overlap bias in the treatment of data, two different categories were used to register relapses:

(a) individual relapses, which were calculated using(I) the number and duration of inpatient admissions; (II) the number and duration of outpatient admissions; (III) the number of visits to emergency services due to deterioration of symptoms; and (IV) the number and duration of deterioration of symptoms requiring intervention by professionals (increase in/change of medication or non-scheduled visits; from the beginning of intervention to the follow-up measurements (18 months and 5 years). If an increase in medication is prescribed in the emergency room, both variables are recorded. However, if the regular psychiatrist (with the aim of preventing a relapse) prescribes the increase in medication, this episode is not considered a relapse.

(b) general relapses: if, in the context of a relapse, more than one of the health care services listed above becomes involved within the same period of time, this episode will be recorded as a single relapse episode (called a "general" relapse). The differentiation between the two strategies used for this variable serves the purpose of avoiding bias in the treatment of the number of relapses (Farriols et al., 2006).

\subsection{Data analysis}

Multivariate analysis of covariance(MANCOVAs) with repeated measures was used to compare differences in symptom change between the PIPE group and the CG at 6, 12, and 18 months. In order to control for the effect of psychotic symptoms, baseline scores and duration of the first admission (days) were used as covariates in the MANCOVAs. Doses of pharmacological treatments were converted to Chlorpromazine-equivalent doses (mg/day) for both groups, with this figure also treated as a covariate (Beers \& Berko, 1999). The effect sizes were calculated by Cohen's Eta-squared $\left(\eta^{2}\right)$. 
Final results were compared to follow-up measurements taken after5 years, using the same tools to assess clinical issues, functioning and relapses.

\section{Results}

The final sample of the study included 62 patients, each of whom was allocated to one of the two experimental conditions: PIPE group $(n=35)$ and control group $(n=27)$ (see Figure 1$)$. None of the patients dropped out of the trial during the treatment or follow-up periods. Data collection for these results was completed seven years after the first patient was recruited, as the sample, recruitment process was progressive during the program and the start times of treatment varied.

The social, demographic and clinical characteristics at baseline were distributed homogeneously between the two groups (see Table 1). In the same way, chlorpromazine-equivalent doses (mg/day) were equivalent in both groups $(\mathrm{p}=.246)$.

\subsection{Clinical and functioning outcomes}

At the time of the baseline assessment, no significant differences were found between the two groups in any of the clinical variables. While it is true that after five years both groups showed an overall improvement with respect to the initial assessment, there were nonetheless some significant differences between the groups. The PIPE group showed notable improvements in all the clinical variables starting in the first six months (the period of the most intense changes), and these values remained constant or continued to improve steadily from one measurement to the next, for all the variables. Meanwhile, the control group's scores for some variables worsened from the initial baseline values to subsequent measurements.

When data were collected 18 months after the start of the treatment, there were significant differences between the groups in the sub-scales of the PANSS in the MANCOVA analysis for repeated measurements. These differences remained in place upon the follow-up measurement after five years (see Table 2).

In terms of positive symptomatology, there was a significant difference between the groups $(\mathrm{p}=$ .02 ) in data collected six months after the start of treatment. Of this variance, $24.3 \%$ was attributable to pharmacological treatment, while a smaller effect $(6 \%)$ is associated with psychological intervention. However, at the test after 18 months these variance proportions changed, with $36 \%$ attributable to the group effect (better in PIPE group) and $8 \%$ to pharmacological treatment. This improvement was still observable in the results of the test conducted five years after the start of treatment, which detected significant differences between the groups, with $34 \%$ of the variance associated with the difference in psychotherapy. In this follow-up test, $10 \%$ of the variance was attributable to pharmacological treatment, and the remaining variance was associated with other factors. The variation between the groups showed moderate-to-low effect sizes $\left(\eta^{2}=.3-.4\right)$ and high degrees of power $(\mathrm{P}>.8)$. 
When measurements were taken after 18 months, significant effect were also found in positive symptomatology (time $\mathrm{x}$ group) (Greenhouse-Geisser, $\mathrm{F}=18.6 ; \mathrm{df}=2 ; \mathrm{p}=.000 ; \eta^{2}=.23 ; \mathrm{P}=.9$ ). However, this results did not remain significant after five years (Greenhouse-Geisser, $F=.46 ; \mathrm{df}=1 ; \mathrm{p}=.5 ; \eta^{2}$ $=.008 ; \mathrm{P}=.1)$.

The results for negative symptomatology were similar $(\mathrm{p}=.048)$, although they showed somewhat lesser effect sizes $\left(\eta^{2}=.1\right)$ and power $(\mathrm{P}=.7)$. Here, $9 \%$ of the variance was attributable to the group factor, while $16 \%$ was associated with the duration (measured in days) of the first psychiatric hospital stay. These proportions of variance remained constant when measurements were taken after 6 and 18 months and upon follow-up testing after 5 years. For these symptoms, the group-time interaction also displayed differences after 18 months (Greenhouse-Geisser, $\mathrm{F}=5.08 ; \mathrm{df}=1 ; \mathrm{p}=.019 ; \eta^{2}=.07 ; \mathrm{P}=.68$ ), although these differences in the group-time interaction were not evident upon assessment after 5 years in comparison with the previous test (Greenhouse-Geisser, $\mathrm{F}=.67 ; \mathrm{df}=1 ; \mathrm{p}=.41 ; \eta^{2}=.01 ; \mathrm{P}=.1$ ).

There were also significant differences between the groups in terms of the general measurements of psychopathology $(\mathrm{p}=.000)$. In the tests after six months, significant differences were found between the groups, but the variance $(8 \%)$ was attributable to the pharmacological treatment. However, at 18 months the variance could be attributed in large part to the effects of psychotherapy ( $49 \%$, the figure reaching 50\% upon follow-up testing after 5 years) with moderate effect sizes $\left(\eta^{2}=.4\right)$ and high degrees of power $(\mathrm{P}=.9)$. In terms of overall psychopathology, there were differences in the group-time interaction at 18 months (Greenhouse-Geisser, $\mathrm{F}=10.79 ; \mathrm{df}=2 ; \mathrm{p}=.001 ; \eta^{2}=.2 ; \mathrm{P}=.9$ ) and after 5 years (Greenhouse-Geisser, $\mathrm{F}=1.2 ; \mathrm{df}=1 ; \mathrm{p}=.038 ; \eta^{2}=.07 ; \mathrm{P}=.55$ ).

The study also evinced an increase in the functioning of both groups, but with significant differences between them $(p=.000)$, with a greater increase in functioning in the group that received the motivational intervention. Upon follow-up testing after 5 years, $32 \%$ of the variance was attributable to the group, with moderate effect sizes $\left(\eta^{2}=.4\right)$ and high power $(\mathrm{P}=.9)$. With regard to the effects of the group-time interaction, the study detected differences at 18 months (Greenhouse-Geisser, $\left.\mathrm{F}=22.46 ; \mathrm{df}=1 ; \mathrm{p}=.000 ; \eta^{2}=.35 ; \mathrm{P}=.9\right)$, but the differences were no longer in place after 5 years (Greenhouse-Geisser, $\mathrm{F}=.7 ; \mathrm{df}=1 ; \mathrm{p}=.37 ; \eta^{2}=.1 ; \mathrm{P}=.14$ ).

There were also differences between the groups in their scores for the Clinical Global Impression scale after 18 months $(p=.01)$ and after five years $(p=.001)$, with a considerable improvement detected in the PIPE group and more stable scores found for the control group. Upon the follow-up test after 5 years, $23 \%$ of the variance was attributed to the group factor. In terms of the effects of the group-time interaction, differences were detected at 18 months (Greenhouse-Geisser, $\mathrm{F}=9.48 ; \mathrm{df}=2 ; \mathrm{p}=.000 ; \eta^{2}$ $=.18 ; \mathrm{P}=.98$ ), but they were not apparent after 5 years (Greenhouse-Geisser, $\mathrm{F}=.246 ; \mathrm{df}=1 ; \mathrm{p}=.622 ; \eta^{2}$ $=.006 ; \mathrm{P}=.077)$.

\subsection{Relapses}


The control group displayed a significantly higher rate of hospitalizations during the treatment process and the follow-up period, evident both in the tests at 18 months $(\mathrm{p}=.037)$ and at 5 years $(\mathrm{p}=.05)$ (see Table 3).

The results for the length in days of hospital stays were along the same lines. The two groups had similar numbers after 6 months, but significant differences between them were observed upon followup testing after 18 months $(\mathrm{p}=.026)$ and 5 years $(\mathrm{p}=.02)$.

With regard to the duration of stays in outpatient hospitals, differences were observed between the groups after 18 months $(\mathrm{p}=.05)$ but not after 5 years, when the number of days was considerably lower for both groups.

The results for emergency room visits were similar to those above, with significant differences between the groups detected at 18 months $(\mathrm{p}=.36)$ but no longer observable after 5 years, due to the reduction in the mean number of ER visits by the members of the control group (although the average number of visits made by the experimental group remained slightly lower).

The PIPE group also displayed a lower rate of general relapses at 18 months than the control group in the generalized linear modal analysis, with the daily dosage of chlorpromazine, the duration of untreated psychosis (DUP) and the length in days of the first hospital admission treated as covariables $(\mathrm{F}=4.3 ; \mathrm{p}=.043)$. In the test conducted after 5 years, although the PIPE group had experienced only half the number of relapses recorded by the control group, the statistical difference was not found to be significant $(\mathrm{p}<.05)$.

There were also considerable differences between the groups in terms of the seriousness of the relapses they experienced. After 5 years, $64.3 \%$ of the patients in the control group had had serious relapses (requiring hospitalization), compared with only $35.7 \%$ of the PIPE group. In the latter group, relapses of a range of different levels of seriousness were reported, with $30.8 \%$ of the cases regarded as mild relapses. However, all the relapses experienced by patients in the control group were reported to be either moderate or serious ( $84.3 \%$ ). These differences between the two groups in terms of the degree of seriousness of relapses were statistically significant $\left(\chi^{2}=6.665 ; \mathrm{p}=.013\right)$.

After 18 months, $48.7 \%$ of the patients in the control group had required an increase in the pharmacological dosage there were prescribed, compared with $25.7 \%$ for the PIPE group. This difference was not statistically significant $\left(\chi^{2}=8.9 ; \mathrm{p}=.062\right)$. After 5 years, the percentages were lower for both groups (PIPE $=26.5 \%$ vs $\mathrm{CG}=29.6 \%$ ), and the difference was not statistically significant $(\mathrm{p}=.785)$.Meanwhile, $34.6 \%$ of the patients in the PIPE group had decreased their dosages at 18 months $\left(\chi^{2}=11.14 ; \mathrm{p}=.001\right)$ and $52 \%$ had done so after 5 years $\left(\chi^{2}=5.2 ; \mathrm{p}=.022\right)$. These figures represented significant differences with respect to the patients in the control group, none of whom recorded decreases in their dosages.

\section{Discussion}


In broad terms, the experimental group in this study arrived at very promising results in terms of their improvement in clinical symptomatology and how they were able to sustain this improvement over time. The results were also positive for overall functioning and relapses.

All the sample attrition occurred during the recruitment phase, representing a total of $40.3 \%$. None of the members of the sample were lost during the treatment and follow-up phases of the research, setting this study apart from others in which the sample attrition rate at five years exceeded $60 \%$ (Turkington et al., 2008).Refusal to participate in studies and abandonment during the course of a study are very common phenomena among the population examined here (Villeneuvea, Potvinc, Lesageb, \& Nicolec, 2010), as patients often display a lack of motivation to undertake treatment (Jochems et al., 2015)and experience great difficulties in sustaining it.

In terms of post-intervention effect sizes, for most of the variables in this study measuring clinical improvements, the results were similar to those found by prior studies involving the use of CBT (Garety et al., 2000; Lynch et al., 2010).

The results of this trial also echoed those of previous research with regard to decreases in positive and negative symptomatology (Barrowclough et al., 2001, 2010, 2014, Hogarty et al., 1986, 1991; Kuipers et al., 1997; Sensky et al., 2000; Tarrier et al., 2004). These similarities also extended to studies that compared the use of motivational interview techniques with other methods, (Barrowclough et al., 2001, 2010, 2014), although none of the prior research featured long-term follow-up with the participants. Obviously, the improvement in treatment compliance with motivational techniques could have an important impact over clinical symptoms.

While it is true that a thorough review of the literature reveals that some other comparative intervention studies using control groups have shown higher effect sizes $\left(\eta^{2}=.33-.40\right)$, these positive and negative clinical results were attained over shorter follow-up periods. When the follow-up periods are of between 12 and 24 months, the effect sizes for positive symptomatology range from .18 to .08 , respectively (Lynch et al., 2010; Sivec \& Montesano, 2012). The effect size on positive and general symptomatology found by this study at 5 years $\left(\eta^{2}=.4\right)$ was greater than in other research, but for negative symptomatology it was smaller $\left(\eta^{2}=.1\right.$, compared to other studies in which the effect has reached .55). In fact, few studies can point to sustained results over a period of 5 years. On exception is Turkington et al. (2008), in which CBT is compared with Treatment-As-Usual (TAU). This study also yielded satisfactory results with regard to severity of symptoms and negative symptomatology, results that were sustained over time. Other research has shown the sustainability of improvements measured using follow-up tests two years after the start of treatment, but in these cases the differences with the control groups are no longer apparent 5 years out (Bertelsen et al., 2008).

The results of this study are also comparable to those of prior research in terms of the improvements observed in patients' overall activity and the clinical impression of patients in treatment (Barrowclough et al., 2001; Haddock et al., 2003). 
This study has produced promising results in terms of relapses (measured by number of rehospitalizations and length of stays), and these promising tendencies remain visible 5 years out. The results of some other studies of relapses are coherent with those collected in this trial(Bechdolf \& Pohlmann, 2012a; Chien, Mui, Cheung, \& Gray, 2015; Sellwood et al., 2001; Sivec \& Montesano, 2012, Turkington et al., 2008). However, other prior research has not found significant results for this variable either 9 months (Barrowclough et al., 2014) or 18 months (Kuipers et al., 1998; Tarrier et al.,2004) from the start of treatment.

It is worth highlighting, however, that the results of CBT vary more greatly when the definition of what constitutes a relapse is more strictly defined to include only rehospitalizations. This study has offered other useful ways to measure the number and severity of relapse episodes. Measured over a period of 5 years, the rate of relapse and the degree of severity of the episodes found in this study were lower than those of other studies, the latter not having reached levels of statistical significance when monitoring patients over the same amount of time (Turkington et al., 2008).

The reduction in days of hospital admission over the first 18 months coincides with the results of other studies (Haddock et al., 2004; O'Donnell et al., 2003). Unlike in other studies that examined the same amount of time (Turkington et al., 2008), here the reduction remained significant 5 years out.

The reduction in dosage levels of medication five years out also coincides with the results of certain past studies (Jackson et al., 2001; Johannessen et al., 2000). Other researchers, however, have not observed any effect on dosage levels over the same monitoring period (Turkington et al., 2008).

We believe that this reduction in medication dosage is connected to the type of intervention carried out with the PIPE group, which consisted of a strategy based on CBT that also included motivational interviews with both patients and their families throughout the process. Without a doubt, schizophrenia patients' motivation to follow and adhere to their treatment plans, and their increase in everyday functioning, both contribute to an improved prognosis for this disorder. The aim of motivational interview techniques is to help foster intrinsic motivation in patients, making them more likely to be committed to their treatment in the long term. As other researchers have posited, we believe that this motivation factor is directly related to the outcomes of treatment (Dolder et al., 2003). Here, it is worth underlining the evolution of the distribution of the variance over the period of this study. At 6 months, a greater proportion of the variance is attributed to pharmacological treatment, but 18 months into the study the psychotherapy received had already started to play a more determining role. This distribution remained intact when the participants were tested 5 years into the study, with psychotherapy explaining as much as $50 \%$ of the variance in the psychopathology variables.

Additionally, psychological interventions that address the emotional impact of the initial schizophrenic episode and its effect on the family can, in the long term, lead to improvements in adaptation, recovery and prevention of relapses. Some researchers have emphasized the importance of taking emotional factors into account, saying that doing so can increase the effectiveness of interventions both by encouraging patients to stick to their treatment plans and by fostering their insight, 
two especially relevant factors when it comes to long-term psychological interventions (Dolder et al., 2003). Given that the "critical period" for patients with schizophrenia comes in the first 5 years, (Birchwood, Todd, \& Jackson, 1998; Lutgens et al., 2015), treatment during this period alleviates the impact of the disorder. Along these lines, other studies incorporating motivational interview techniques have also attained excellent results (Barrowclough, 2011; Barrowclough et al., 2010; Beebe et al., 2012; Farholm \& Sørensen, 2016; Fiszdon et al., 2016; Haddock et al., 2004; Vanderwaal, 2015; Wai et al., 2015).

We think that the results of the experimental group are due to the fact that the group had a more complete and better treatment than TAU that only received pharmacological treatment, nursing care and social work. The attribution of the variance during the evaluation periods shows that both groups improved clinically and functionally but that the improved treatment of the PIPE group has been able to contribute to good long-term results.

This study is not without its limitations. It used a reduced sample size because it required an intense, longitudinal intervention that necessitated the involvement of a large number of researchers with clinical experience. It would also have been interesting to take more intermediate measurements, perhaps every six months, during the course of the study, and to include additional co-variables such as adherence to pharmacological treatment and the differences in the amount of community resources devoted to the patients in the two groups over the period.

Another limitation is that therapeutic compliance was not evaluated psychometrically. Part of the improvement of both groups is due to the adherence to treatment with IM (PIPE group) and through psychoeducation in nursing care (control group). The level of compliance is also related to good results. There is obviously an improvement, that this is greater in the experimental group and that it is maintained longer than in the control group. For future studies, it would be good to include compliance measures as covariates and include another treatment group with CBT with pharmacological treatment in addition to TAU group. Also it would be interesting to be able to differentiate the influence of each of the different treatment ingredients of PIPE. Bearing in mind that this program has been carried out with the motivational techniques in all the interventions done in both (family and individual format).

To conclude, the results obtained in this study give reason for hope. Treatment during the early phase of schizophrenia plays an important role in contributing to clinical improvements and better daily functioning. The combination of improved clinical follow-up (including cognitive therapy, family intervention and motivational techniques) may offer better results during the intervention and in the long term clinical improvements.

\section{Acknowledgements}

Funding: This work was supported by a pre-doctoral grant for the Training of Research Personnel (FI) 2003FI-0932 awarded by the Departament d'Universitats, Recerca i Societat de la Informació (DURSI, Government of Catalonia). Seny Foundation for Schizophrenia. 
References

American Psychiatric Association. (2000). Diagnostic and statistical manual of mental disorders (4.a ed. rev.). Washington, DC: American Psychiatric Association.

Baker, A., Lewin, T., Reichler, H., Clancy, R., Carr, V., Garrett, R., ... Terry, M. (2002).

Motivational interviewing among psychiatric in-patients with substance use disorders. Acta Psychiatrica Scandinavica, 106(3), 233-240.

Barrowclough, C. (2011). A randomized controlled trial of integrated motivational interviewing and cognitive behavior therapy (mi-cbt) for people with a schizophrenia diagnosis and substance misuse - the midas trial. Schizophrenia Bulletin, 37, 295.

Barrowclough, C., Haddock, G., Tarrier, N., Lewis, S. W., Moring, J., O’Brien, R., .. McGovern, J. (2001). Randomized controlled trial of motivational interviewing, cognitive behavior therapy, and family intervention for patients with comorbid schizophrenia and substance use disorders. American Journal of Psychiatry, 158(10), 1706-1713.

https://doi.org/10.1176/appi.ajp.158.10.1706

Barrowclough, C., Haddock, G., Wykes, T., Beardmore, R., Conrod, P., Craig, T., ... Tarrier, N. (2010). Integrated motivational interviewing and cognitive behavioural therapy for people with psychosis and comorbid substance misuse: randomised controlled trial. British Medical Journal, 341, c6325. https://doi.org/https://doi.org/10.1136/bmj.c6325

Barrowclough, C., Marshall, M., Gregg, L., Fitzsimmons, M., Tomenson, B., Warburton, J., \& Lobban, F. (2014). A phase-specific psychological therapy for people with problematic cannabis use following a first episode of psychosis: a randomized controlled trial. Psychological Medicine, 44(13), 2749-2761. https://doi.org/10.1017/S0033291714000208

Beaumont, E., Galpin, A., \& Jenkins, P. (2012). 'Being kinder to myself ': A prospective comparative study, exploring post-trauma therapy outcome measures, for two groups of clients, receiving either cognitive behaviour therapy or cognitive behaviour therapy and compassionate mind training. Counselling Psychology Review, 27(1), 31-43.

Bechdolf, A., \& Pohlmann, B. . G. (2012a). Motivationsbehandlung für Patienten mit der Doppeldiagnose Psychose und Sucht. Der Nervenarzt, 83(7), 888-896.

Bechdolf, A., \& Pohlmann, B. G. (2012b). State-dependent motivational interviewing for people with schizophrenia and substance use. Results of a randomised controlled trial. Der Nervenarzt, 83(7), 888-896.

Beebe, L., Smith, K., Burk, R., McIntyre, K., Dessieux, O., Tavakoli, A., ... Velligan, D. (2011). Effect of a Motivational Intervention on Exercise Behavior in Persons with Schizophrenia Spectrum Disorders. Community Mental Health Journal, 47(6), 628-636.

https://doi.org/10.1007/s10597-010-9363-8 
Beebe, L., Smith, K., Velligan, B., McIntyre, K., Dessieux, O., \& Tavakoli, A. (2012). Motivational intervention increases exercise in schizophrenia and co-occurring substance use disorders. Schizophrizophrenia Research, 135(1-3), 204-205.

Beers, M., \& Berko, R. (1999). El Manual Merck de diagnóstico y tratamiento (10a ed.). Madrid: Harcourt.

Bertelsen, M., Jeppesen, P., Petersen, L., Thorup, A., Øhlenschlaeger, J., le Quach, P., ... Nordentoft, M. (2008). Five-year follow-up of a randomized multicenter trial of intensive early intervention vs standard treatment for patients with a first episode of psychotic illness: the OPUS trial. ArchIives of General Psychiatry, 65(7), 762-771. https://doi.org/doi: 10.1001/archpsyc.65.7.762.

Birchwood, M., \& Tarrier, N. (1995). El tratamiento psicológico en la esquizofrenia. Barcelona: Ariel.

Birchwood, M., Todd, P., \& Jackson, C. (1998). Early intervention in psychosis. The critical period hypothesis. British Journal of Psychiatry Suppl., 172(33), 53-59.

Chien, W., Mui, J., Cheung, E., \& Gray, R. (2015). Effects of motivational interviewing-based adherence therapy for schizophrenia spectrum disorders: a randomized controlled trial. Trials, 16, 270. https://doi.org/10.1186/s13063-015-0785-z

Corrigan, P., McCracken, S., \& Holmes, E. (2001). Motivational interviews as goal assessment for persons with psychiatric disability. Community Ment Health Journal, 37(2), 113-122.

Depp, C., Lebowitz, B., TL, P., Lacro, J., \& Jeste, D. (2007). Medication adherence skills training for middle-aged and elderly adults with bipolar disorder: development and pilot study. Bipolar Disorders, 9(6), 636-645.

Dolder, C., Lacro, J., Leckband, S., \& Jeste, D. (2003). Interventions to improve antipsychotic medication adherence: review of recent literature. Journal of Clinical Psychopharmacology, 23(4), 389-399.

Drake, R., Nordentoft, M., Haddock, L., Arango, C., Fleischhacker, W., Glenthøj, B., ... Kahn, R. (2015). Modeling determinants of medication attitudes and poor adherence in early nonaffective psychosis: implications for intervention. Schizophrenia Bulletin, 41(3), 584-596.

Eack, S., Greenwald, D., Hogarty, S., \& Keshavan, M. (2010). One-year durability of the effects of cognitive enhancement therapy on functional outcome in early schizophrenia. Schizophrenia Research, 120(1-3), 210-216. https://doi.org/10.1016/j.schres.2010.03.042

Eack, S., Hogarty, S., Bangalore, S., Cornelius, J., \& Keshavan, M. (2016). Patterns of Substance Use during Cognitive Enhancement Therapy: An 18-Month Randomized Feasibility Study. Journal of Dual Diagnosis, 12(1), 74-82. https://doi.org/10.1080/15504263.2016.1145778

Eack, S., Mesholam-Gately, R., Greenwald, D., Hogarty, S., \& Keshavan, M. (2013). Negative symptom improvement during cognitive rehabilitation: results from a 2-year trial of Cognitive Enhancement Therapy. Psychiatry Research, 209(1), 21-26. 
https://doi.org/10.1016/j.psychres.2013.03.020

Eack, S., Newhill, C., \& Keshavan, M. (2016). Cognitive Enhancement Therapy Improves RestingState Functional Connectivity in Early Course Schizophrenia. Journal of Social Work Research., $7(2), 211-230$.

Farholm, A., \& Sørensen, M. (2016). Motivation for physical activity and exercise in severe mental illness: A systematic review of intervention studies. Int Ernational Journal of Mental Health Nursing, 25(3), 194-205. https://doi.org/10.1111/inm.12214

Farriols, N., Palma, C., Ramos, M., Fernandez, M., Chamorro, A., Polo, Y., \& Botella, L. (2006). Efectividad de un programa de intervención psicosocial en pacientes psicóticos crónicoso. Clínica y Salud, 17(2), 171-185.

First, M. B., Spitzer, R. L., Gibbon, M., \& Williams, J. B. W. (1995). Structured Clinical Interview for DSM-IV (SCID-I).Research Version. Biometrics Research Department. New York: Psychiatric Institute.

Fiszdon, J., Kurtz, M., Choi, J., Bell, M., \& Martino, S. (2016). Motivational Interviewing to Increase Cognitive Rehabilitation Adherence in Schizophrenia. Schizophrenia Bulletin, 42(2), 327-334. https://doi.org/10.1093/schbul/sbv143

Garety, P., Fowler, D., \& Kuipers, E. (2000). Cognitive-behavioral therapy for medication-resistant symptoms. Schizophrenia Bulletin, 26(1), 73-86.

Graeber, D., Moyers, T., Griffith, G., Guajardo, E., \& Tonigan, S. (2003). Addictions services. A pilot study comparing motivational interviewing and an educational intervention in patients with schizophrenia and alcohol use disorders. Community Mental Health Journal, 39(3), 189-202.

Haddock, G., Barrowclough, C., Tarrier, N., J, M., O’Brien, R., Schofield, N., ... Lewis, S. (2004). Cognitive-behavioural therapy and motivational intervention for schizophrenia and substance misuse. 18-month outcomes of a randomised, controlled trial. Current Medical Literature: Psychiatry, 15(2), 49-49.

Haddock, G., Barrowclough, C., Tarrier, N., Moring, J., O’Brien, R., Schofield, N., ... Lewis, S. (2003). The British Journal Of Psychiatry: The Journal Of Mental Science. CognitiveBehavioural Therapy and Motivational Intervention for Schizophrenia and Substance Misuse. 18-Month Outcomes of a Randomised Controlled Trial., 183, 418. Retrieved from http://mendeley.csuc.cat/fitxers/10b1ca8336f86ef3f39a74419b03000f

Hogarty, G., Anderson, C., Reiss, D., Kornblith, S., Greenwald, D., Javna, C., ... Group., E. S. R. (1986). Family psychoeducation, social skills training, and maintenance chemotherapy in the aftercare treatment of schizophrenia. I. One-year effects of a controlled study on relapse and expressed emotion. Archives of General Psychiatry, 43, 633-642.

Hogarty, G., Anderson, C., Reiss, D., Kornblith, S., Greenwald, D., Ulrich, R., ... EPICS Schizophrenia Research Group. (1991). Family Psychoeducation, social skills training, and maintenance chemotherapy in the aftercare treatment of schizophrenia: II. Two-year effects of a 
controlled study on relapse and adjustment. Archives of General Psychiatry, 48, 340-347.

Jackson, H., McGorry, P., Henry, L., Edwards, J., Hulbert, C., \& Harrigan. (2001). Cognitively oriented psychotherapy for early psychosis (COPE): a 1-year follow-up. British Journal of Clinical Psychology, 40, 57-70.

Jenner, J., Nienhuis, F., Wiersma, D., \& van de Willige, G. (2004). Hallucination focused integrative treatment: a randomized controlled trial. Schizophrenia Bulletin, 30(1), 133-145.

Jochems, E., van Dam, A., Duivenvoorden, H., Scheffer, S., \& van der Feltz-Cornelis, CM Niels, L. (2015). Different Perspectives of Clinicians and Patients with Severe Mental Illness on Motivation for Treatment. Clinical Psychology \& Psychotherapy, (5), 438-451. https://doi.org/DOI: 10.1002/cpp.1971

Johannessen, J., Larsen, T., McGlashan, T., \& Vaglum, P. (2000). Early intervention in psychosis: The TIPS project, a multi-centre study in Scandinavia. In A. B. \& B. Martindale (Ed.), Psychosis: Psychological approaches and their effectiveness (pp. 210-234). London: Gaskell.

Kay, S., Fiszbein, L., \& Opler, A. (1987). The Positive and Negative Syndrome Scale (PANSS) for Schizophrenia. Schizophrenia Bulletin, 13(261-276).

Keet, I., Hulstijn, K., de Haan, L., Schippers, G., \& Linszen, D. (2006). Family motivational intervention: Training motivational interviewing for family members of patients with schizophrenia, cannabis use and poor compliance. Schizophrenia Research, 86 supplem, S149.

Kemp, R., Hayward, P., Applewhaite, G., Everitt, B., \& David, A. (1996). Compliance therapy in psychotic patients: randomised controlled trial. British Journal of Psychiatry, 312(7027), 345349.

Kemp, R., Kirov, G., Everitt, B., Hayward, P., \& David, A. (1998). Randomised controlled trial of compliance therapy. 18-month follow-up. British Journal of Psychiatry, 172, 413-419.

Keshavan, M., Eack, S., Prasad, K., Haller, C., \& Cho, R. (2016). Longitudinal functional brain imaging study in early course schizophrenia before and after cognitive enhancement therapy. Neuroimage, 151, 55-64. https://doi.org/10.1016/j.neuroimage.2016.11.060

Kuipers, E., Garety, P., Fowler, D., Bebbington, G., Freeman, D., \& Hadley, C. (1997). London East Anglia randomised controlled trial of cognitive-behavioural therapy for psychosis.No Title. British Journal of Psychiatry, 171, 319-327.

La Pietra, E. (2006). The impact of motivational interviewing on initial treatment attendance for participants with dual diagnosis. Humanities and Social Sciences, 56, 726-727.

Lutgens, D., Iyer, S., Joober, R., Brown, T., Norman, R., Latimer, E., ... Malla, A. (2015). A fiveyear randomized parallel and blinded clinical trial of an extended specialized early intervention vs. regular care in the early phase of psychotic disorders: study protocol. BMC Psychiatry, 15(22). https://doi.org/doi.org/10.1186/s12888-015-0404-2

Lynch, D., Laws, K. R., \& McKenna, P. J. (2010). Cognitive behavioural therapy for major psychiatric disorder: does it really work? A meta-analytical review of well-controlled trials. 
Psychiatry Research, 40(1), 9-24.

Martino, S., Carroll, K., Nich, C., \& Rounsaville, B. (2006). A randomized controlled pilot study of motivational interviewing for patients with psychotic and drug use disorders. Addiction, 101(10), 1479-1492.

Martino, S., Carroll, K., O’Malley, S., Rounsaville, B., Martino, S., Carroll, K., ... Rounsaville, B. (2000). Motivational interviewing with psychiatrically ill substance abusing patients. American Journal on Addictions, 9(1), 88-91.

McCracken, S., \& Corrigan, P. (2008). Motivational Interviewing for Medication Adherence in Individuals with Schizophrenia. In S. H. Arkowitz , H.A. Westra., W.R. Miller \& S. Rollnick (Ed.), Motivational interviewing in the treatment of psychological problems (pp. 249-276). New York: Guilford Press.

Miller, R., \& Mason, S. (2004). Cognitive enhancement therapy: a therapeutic treatment strategy for first-episode schizophrenia patients. Bulletin of the Menninger Clinic, 68(3), 213-230.

Miller, R., \& Rollnick, S. (1991). Motivational interviewing: preparing people to change addictive behavior. New York: Guilford Press.

National Institute of Mental Health. (1976). Clinical Global Impressions. In ed. E. R. Guy W (Ed.), Assesment Manual for Psychopharmacology, rev ed. (pp. 217-222). Maryland.

O’Donnell, C., Donohoe, G., Sharkey, L., Owens, N., Migone, M., Harries, R., ... O’Callaghan, E. (2003). Compliance therapy: a randomised controlled trial in schizophrenia. British Medical Journal, 327(7419), 834.

Palma, C. (2015). Intervención psicoterapéutica en la fase inicial de la esquizofrenia. Germany: Publicia.

Palma, C., Cañete, J., Farriols, N., Cebrià, J., Michael, M., Alonso, I., ... G, S. (2011). Randomised controlled trial of cognitive-motivational therapy program for the initial phase of schizophrenia: a 6-month assessment. European Journal of Psychiatry, 25(2), 68-80.

Palma, C., Cebrià, J., Farriols, N., Cañete, J., \& Muñoz, E. (2005). La entrevista motivacional con el paciente esquizofrénico. Psiquis, 26109(3), 109-120.

Peralta, V., \& Cuesta, M. (1994). Validación de la escala de los síndromes positivo y negativo (PANSS) en una muestra de esquizofrénicos españoles. Actas Luso-Españolas de Neurología y Psiquiatría, 22(4), 171-177.

Pfammatter, M., Junghan, U., \& Brenner, H. (2006). Efficacy of psychological therapy in schizophrenia: conclusions from meta-analyses. Schizophrenia Bulletin, 32(Suppl 1), S64-S6480.

Rothwell, N., \& Duffy, L. (1999). Towards an integrated psychotherapeutic approach in psychosis: three case studies. Clinical Psychology \& Psychotherapy, 6(3), 227-235.

Rusch, N., \& Corrigan, P. W. (2002). Motivational interviewing to improve insight and treatment adherence in schizophrenia. Psychiatric Rehabilitation Journal, 26(1), 23-32. 
Sellwood, W., Mainwaring, J., Barrowclough, C., Tarrier, N., Lewis, S., \& Quinn, J. (2001). Needsbased cognitive-behavioural family intervention for carers of patients suffering from schizophrenia: 12-Month follow-up. Acta Psychiatrica Scandinavica, 104(5), 346.

Sensky, T., Turkington, D., Kingdon, D., Scott, J., Scott, J., Siddle, R., ... Barnes, T. (2000). A randomized controlled trial of cognitive-behavioural therapy for persistent symptoms in schizophrenia resistant to medication. Archives of General Psychiatry, 57, 165-172.

Sivec, H. J., \& Montesano, V. L. (2012). Cognitive Behavioral Therapy for Psychosis in Clinical Practice. Psychotherapy (Chic)., 49(2), 258-270. https://doi.org/doi: 10.1037/a0028256.

Steinberg, M., Ziedonis, D., Krejci, J., \& Brandon, T. (2004). Motivational interviewing with personalized feedback: a brief intervention for motivating smokers with schizophrenia to seek treatment for tobacco dependence. Journal of Consulting and Clin Psychology, 72(4), 723-728.

Swanson, A., Pantalon, M., \& Cohen, K. (1999). Motivational interviewing and treatment adherence among psychiatric and dually diagnosed patients. Journal of Nervous and Mental Disease, 187(10), 630-635.

Tarrier, N., Lewis, S., Haddock, G., Bentall, R., Drake, R., Kinderman, P., ... Dunn, G. (2004). Cognitive-behavioural therapy in first-episode and early schizophrenia. 18-month follow-up of a randomised controlled trial. British Journal of Psychiatry, 184, 231-239.

Trials.

Turner, D. T., van der Gaag, M., Karyotaki, E., \& Cuijpers, P. (2014). Psychological Interventions for Psychosis: A Meta-Analysis of Comparative Outcome Studies. American Journal of Psychiatry, $171(5), 523-538$.

Vanderwaal, F. (2015). Impact of Motivational Interviewing on Medication Adherence in Schizophrenia. Mental Health Nursing, 36(11), 900-904. https://doi.org/10.3109/01612840.2015.1058445

Villeneuvea, K., Potvinc, S., Lesageb, A., \& Nicolec, L. (2010). Meta-analysis of rates of drop-out from psychosocial treatment among persons with schizophrenia spectrum disorder. Schizophrenia Research, 121(1-3), 266-270.

Wai, T., Mui, J., Cheung, E., \& Gray, R. (2015). Effects of motivational interviewing-based adherence therapy for schizophrenia spectrum disorders: a randomized controlled trial. Trials, $16(1), 1-14$.

Westermann, S., \& Cavelti, M. H. (2015). Motive-oriented therapeutic relationship building for patients diagnosed with schizophrenia. Frontiers in Psychology, 6(1294). https://doi.org/10.3389/fpsyg.2015.01294

Westra, H., Aviram, A., \& Doell, F. (2011). Extending motivational interviewing to the treatment of major mental health problems: current directions and evidence. Canadian Journal of Psychiatry, $56(11), 643-650$.

Wiersma, D., Jenner, J., Nienhuis, F., Stant, D., \& van de Willige, G. (2004). Improvement of quality 
of life of schizophrenia patients with persistent auditory hallucinations by means of integrated treatment: is it cost-effective? Acta PsychiatrIica Scand Inavica, 110(421 suppl.), 58.

Wojtalik, J., Hogarty, S., Cornelius, J., Phillips, M., Keshavan, M., Newhill, C., \& Eack, S. (2016). Cognitive Enhancement Therapy Improves Frontolimbic Regulation of Emotion in Alcohol and/or Cannabis Misusing Schizophrenia: A Preliminary Study. Journal of Social Work Research., 7(2), 211-230. 
